\title{
THEORETICAL STUDY OF INFLUENCE OF MODIFICATION OF THE METAL SURFACE ON MAGNITUDE OF THE FIELD EMISSION CURRENT IN GRADIENT-STABLE ACCELERATING STRUCTURES
}

\author{
I. I. Musiienko*, R. I. Kholodov \\ Institute of Applied Physics, National Academy of Sciences of Ukraine, Sumy, Ukraine
}

(Received July 26, 2018)

\begin{abstract}
Quantum-mechanical problem on electron motion through the model potential barrier of the metal-vacuum system with an additional near-surface dipole layer is considered. Taking into account the continuity conditions of the wave functions and their derivatives at the interface between the two media, general expressions of the coefficient of transparency of the potential barrier and a current density of field emission is obtained in the framework of this model. It is shown the influence of the effective thickness of the dipole layer of the metal surface on a value of the field emission current density.
\end{abstract}

PACS: 537.533.2:539.182

\section{INTRODUCTION}

Despite the fact that the theory of field emission under influence of external electromagnetic fields, written by Fowler and Nordheim in the 20 years of the last century [1], this topic is relevant, in particular, in the task of overcoming high-gradient breakdowns in accelerating structures for receiving charged particles of high energies on modern accelerators. Field emission is one of the stages of occurrence of high-gradient breakdown in accelerating structures.

Experiments on the modeling accelerator structures of the compact linear electron-positron accelerator in the CLIC (Compact Linear Collider) project, carried out at the European Center for Nuclear Research, CERN, showed that when introducing power of a high-frequency electromagnetic field, which provides the electric field strength on the accelerating axis a value of the order of $100 \mathrm{MV} / \mathrm{m}$, highfrequency high-vacuum breakdowns arise on the surface of the accelerating structure [2-4]. Therefore, when CERN begins to design the CLIC accelerator, the problem of high-vacuum high-gradient breakdowns is arisen.

Since each breakdown leads to a loss of the density of the charged particle beam and to damage of the surface of material, various methods of increasing the resistance to high-gradient breakdown of the accelerating structure are being investigated. One way to eliminate the problem of high-vacuum high-gradient breakdowns is to reduce the current density of the field emission. At this stage, CERN studies conditioning of the surface of electrodes to increase the stability of metal surface of accelerating structures to high-gradient breakdowns [2]. Other possible ways to overcome high-gradient breakdowns are implantation of some elements, (for example, argon, nitrogen, zirconium ions) into the near-surface layer of the metal; vacuum coating of a more refractory metal film on the surface; desorption of molecules of gases from the surface of the metal; the location of the accelerating structure in an external magnetic field.

In the works $[5,6]$ the influence of the magnetic field on the field emission current is theoretically investigated. Theoretically in [6] was shown a change of the potential barrier under the influence of a magnetic field parallel to the metal surface and provides the ability to reduce the probability of breakdown and increase the stability of accelerating structures to high-gradient breakdowns by introducing them into a magnetic field system.

In the investigation [7], the potential barrier model for two W-Cs systems was considered: with a thin layer and a hyperfine layer of cesium. The effect of equa-lizing the Fermi levels of the two-metal system in the dipole layer and the value of the work functions of each component of the metal-metal system are taken into account. A similar form of a potential barrier was considered in works $[8,9]$, in which the authors theoretically described the field emission of electrons from nanoscale objects for the barrier depicted in Fig.1. In the work [8] the author has showed the effect of the Coulomb blockade phenomenon on the magnitude of the field emission current.

The purpose of this paper is to generalize FowlerNordheim theory of field emission from a metal with an additional near-surface dipole layer.

*E-mail address: igor-musienko@ukr.net 


\section{FIELD CURRENT FROM A METAL WITH AN ADDITIONAL NEAR-SURFACE DIPOLE LAYER}

Fowler and Nordheim [1] obtained the formula for the current density of field emission on the basis of finding the transparency coefficient of the potential barrier $\mathrm{D}(\mathrm{W})$ as a function of the electron energy $\mathrm{W}$ at the boundary from the metal to the vacuum. In this case, the continuity conditions of the wave functions and their derivatives were used at the interface between the two media. The transparency coefficient is defined as the ratio of the flux density of the wave passing through the barrier to the density of the falling wave flux:

$$
D(W)=\frac{j_{1}}{j_{0}},
$$

where $j_{1}, j_{0}$ are the density fluxes of the wave passing through the barrier and the falling wave, respectively.

The density of the field current $j$ is given by:

$$
j=e \cdot \int_{0}^{\infty} D(W) \cdot N(W) d W,
$$

where $D(W)$ is the coefficient of transparency of the potential barrier; $N(W)$ is the number of electrons incident on a surface of unit area per unit time with a kinetic energy $W$ normal to the surface; $e$ is the electron charge. From expression (2) one can obtain the Fowler-Nordheim formula for current density:

$$
\begin{gathered}
j_{F-N}=\frac{e}{4 \cdot \pi^{2} \cdot \hbar} \cdot \frac{\sqrt{\mu}}{(\mu+\chi) \cdot \sqrt{\chi}} . \\
\cdot F^{2} \cdot \exp \left(-\frac{4 k}{3 F} \cdot \chi^{\frac{3}{2}}\right),
\end{gathered}
$$

where $F=e \cdot E ; E$ is constant electric field strength; $\chi$ is the work function; $\mu$ is the usual parameter of the electron distribution in the Fermi-Dirac statistics equivalent to the thermodynamic partial potential of an electron; $k=\frac{\sqrt{2 \cdot m}}{\hbar} ; m$ is the free electron mass [1].

Let's consider the phenomenological model of the potential barrier of the metal-vacuum system, which is depicted in Fig.1. It is shown that the region I is the inner region of the metal, region II is the effective thickness $d$ of the near-surface dipole layer, the region II and III are regions of metal modification, and the IV region is the potential barrier at the metal-vacuum interface. Height $C$ of the second and fourth area, depicted in Fig.1 is equal to the sum of the work function $\chi$ of the investigated metal and its the thermodynamic partial potential of an electron $\mu, C=\mu+\chi$. It is possible to use the introducing such layer in order to describe the metal with modification of the metal surface. One can suppose that the effective thickness of the dipole layer is a sum of a volumes of all creating defects and emptiness of a modified metal surface. For example, one of the methods of defect formation is bombarding the surface of the copper structure by high-energy beams of copper ions. The size of the effective thickness $d$ of the dipole layer can be estimated using the simple formula:

$$
d=n \cdot h \cdot V,
$$

where $n$ is the concentration of the formed defects, $h$ is the thickness of surface modification, $V$ is the point defect volume, $p=h+d$.

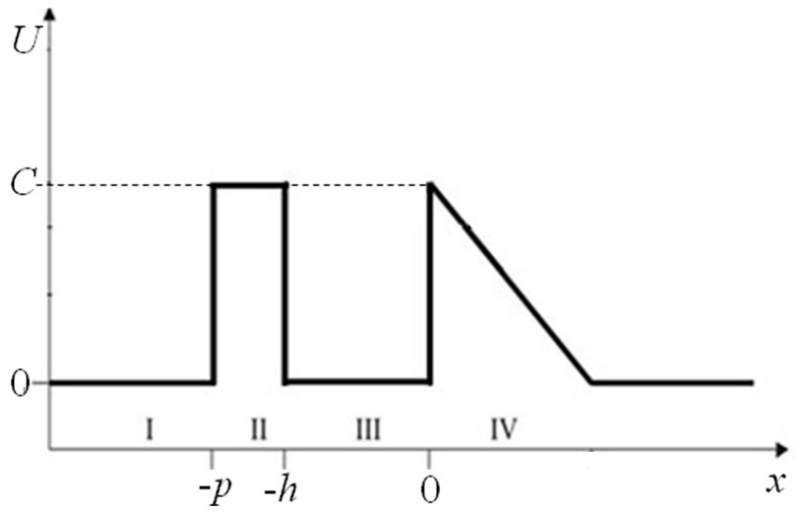

Fig.1. Diagram of the potential barrier for the escape of electrons from a modified metal surface to vacuum

The wave functions for each of the regions of the potential barrier have the form:

$$
\begin{gathered}
\Psi_{1}=A_{1} \cdot \exp \left(i \cdot k_{1} \cdot x\right)+B_{1} \cdot \exp \left(-i \cdot k_{1} \cdot x\right), \\
\Psi_{2}=A_{2} \cdot \exp (-\beta \cdot x)+B_{2} \cdot \exp (\beta \cdot x), \\
\Psi_{3}=A_{3} \cdot \exp \left(i \cdot k_{1} \cdot x\right)+B_{3} \cdot \exp \left(-i \cdot k_{1} \cdot x\right), \\
\Psi_{4}=\sqrt{\left(-\frac{C-W}{F}+x\right)}\left(k^{2} \cdot F\right)^{\frac{1}{6}} \cdot \\
\cdot H_{\frac{1}{3}}^{(2)}\left(\frac{2}{3} \cdot k \cdot \sqrt{F}\left(-\frac{C-W}{F}+x\right)^{\frac{3}{2}}\right),
\end{gathered}
$$

where $A_{1}, B_{1}, A_{2}, B_{2}, A_{3}, B_{3}$ is complex amplitudes of wave functions; $k_{1}=\frac{\sqrt{2 \cdot m \cdot W}}{\hbar} ; \beta=\frac{\sqrt{2 \cdot m \cdot(C-W)}}{\hbar}$. The wave function and its partial derivatives must be single-valued and continuous [10]. Conditions for the continuity of the wave functions on the boundaries of these regions (see Fig.1) have the form:

$$
\begin{aligned}
\Psi_{1}(-p) & =\Psi_{2}(-p), \\
\Psi_{1}^{\prime}(-p) & =\Psi_{2}^{\prime}(-p), \\
\Psi_{2}(-h) & =\Psi_{3}(-h), \\
\Psi_{2}^{\prime}(-h) & =\Psi_{3}^{\prime}(-h), \\
\Psi_{3}(0) & =\Psi_{4}(0), \\
\Psi_{3}^{\prime}(0) & =\Psi_{4}^{\prime}(0) .
\end{aligned}
$$

As a result, we obtain a system of equations for finding complex amplitudes: 


$$
\begin{array}{r}
A_{1} \cdot \exp \left(-i \cdot k_{1} \cdot p\right)+B_{1} \cdot \exp \left(i \cdot k_{1} \cdot p\right)=A_{2} \cdot \exp (\beta \cdot p)+B_{2} \cdot \exp (-\beta \cdot p), \\
i \cdot k_{1} \cdot A_{1} \cdot \exp \left(-i \cdot k_{1} \cdot p\right)-i \cdot k_{1} \cdot B_{1} \cdot \exp \left(i \cdot k_{1} \cdot p\right)=-A_{2} \cdot \beta \cdot \exp (\beta \cdot p)+B_{2} \cdot \beta \cdot \exp (-\beta \cdot p), \\
A_{2} \cdot \exp (\beta \cdot h)+B_{2} \cdot \exp (-\beta \cdot h)=A_{3} \cdot \exp \left(-i \cdot k_{1} \cdot h\right)+B_{3} \cdot \exp \left(i \cdot k_{1} \cdot h\right), \\
-A_{2} \cdot \beta \cdot \exp (\beta \cdot h)+B_{2} \cdot \beta \cdot \exp (-\beta \cdot h)=i \cdot k_{1} \cdot A_{3} \cdot \exp \left(-i \cdot k_{1} \cdot h\right)-i \cdot k_{1} \cdot B_{3} \cdot \exp \left(i \cdot k_{1} \cdot h\right), \\
A_{3}+B_{3}=\sqrt{\frac{C-W}{F}} \cdot \exp \left(-\frac{\pi \cdot i}{2}\right) \cdot\left(k^{2} \cdot F\right)^{\frac{1}{6}} \cdot H_{\frac{1}{3}}^{(2)}\left(\exp \left(-\frac{3 \cdot \pi \cdot i}{2}\right) \cdot Q\right), \\
i \cdot k_{1} \cdot A_{3}-i \cdot k_{1} \cdot B_{3}=\frac{1}{2} \cdot\left(\frac{C-W}{F}\right)^{-\frac{1}{2}} \cdot \exp \left(\frac{\pi \cdot i}{2}\right) \cdot\left(k^{2} \cdot F\right)^{\frac{1}{6}} \cdot H_{\frac{1}{3}}^{(2)}\left(\exp \left(-\frac{3 \cdot \pi \cdot i}{2}\right) \cdot Q\right)- \\
-\left(\frac{C-W}{F}\right) \cdot k \sqrt{F} \cdot\left(k^{2} \cdot F\right)^{\frac{1}{6}} \cdot \exp \left(\frac{3 \cdot \pi \cdot i}{2}\right) \cdot \frac{d H_{\frac{1}{3}}^{(2)}\left(\exp \left(-\frac{3 \cdot \pi \cdot i}{2}\right) \cdot Q\right)}{d Q},
\end{array}
$$

where $Q=\frac{2}{3} \cdot k \cdot \sqrt{F} \cdot\left(\frac{C-W}{F}\right)^{\frac{3}{2}}$.

The analytical form of the complex amplitudes $A_{3}$ and $B_{3}$ can be obtained using the results of the work [1].

The coefficient of transparency of the barrier $D(W)$ in accordance with (1), taking into account the absence of sources of particles, one can find by the formula:

$$
D(W)=\frac{\left|B_{1}\right|^{2}-\left|A_{1}\right|^{2}}{\left|B_{1}\right|^{2}}=1-\frac{\left|A_{1}\right|^{2}}{\left|B_{1}\right|^{2}} .
$$

In general case the coefficient $D(W)$ depends on parameters: $W, F, \mu, \chi, d, h$ and its analysis is done by the numerical method. If $d \rightarrow 0 D(W)$ becomes like on expression that obtained by Fowler and Nordheim [1]:

$$
\begin{aligned}
& D_{F-N}=\frac{4 \cdot \sqrt{W \cdot(C-W)}}{C} . \\
& \cdot \exp \left(-\frac{4 \cdot k \cdot(C-W)^{\frac{3}{2}}}{3 \cdot F}\right) .
\end{aligned}
$$

The coefficient $D(W)$ is obtained by the numerical method in general case on conditions

$$
\begin{aligned}
& k_{1} \cdot d<<1, \beta \cdot d<<1, \\
& k_{1} \cdot h<<1, \beta \cdot h<<1,
\end{aligned}
$$

one can simplify to such analytical form:

$$
D(W)=D_{F-N} \cdot\left(1-\frac{d}{d_{0}(W)}\right),
$$
where $d_{0}(W)=\left(\frac{F}{C-W}+2 \cdot \frac{\sqrt{2 \cdot m}}{\hbar} \cdot \sqrt{C-W}\right)^{-1}$.
In this approximation the finding expression for $D(W)$ do not depend on the thickness of surface modification $h$. Notice that on conditions (13) $d<<d_{0}$ for all $W$. At the value $F=5 \cdot 10^{9} \mathrm{eV} / \mathrm{m}$ for the copper characteristics: $C=12 \mathrm{eV}, \mu=7.5 \mathrm{eV}$, $\chi=4.5 \mathrm{eV}, W=\mu, d_{0}(\mu)=0.5 \cdot 10^{-10} \mathrm{~m}^{-1}$.

In Fig.2 one can see dependences $D(d)$ at aforementioned parameters, that are calculated by the equations (12) (a continuous curve) and (14) (the line is depicted by dots). Dependence that are shown by dot-dash line in Fig.2 describes the numerical calculations $D(d)$ at $h=10^{-11} \mathrm{~m}$. In Fig.2 the graph of the dependence of the analytic formula (14) are similar to the dependence $D(d)$, that are calculated by the numerical method.

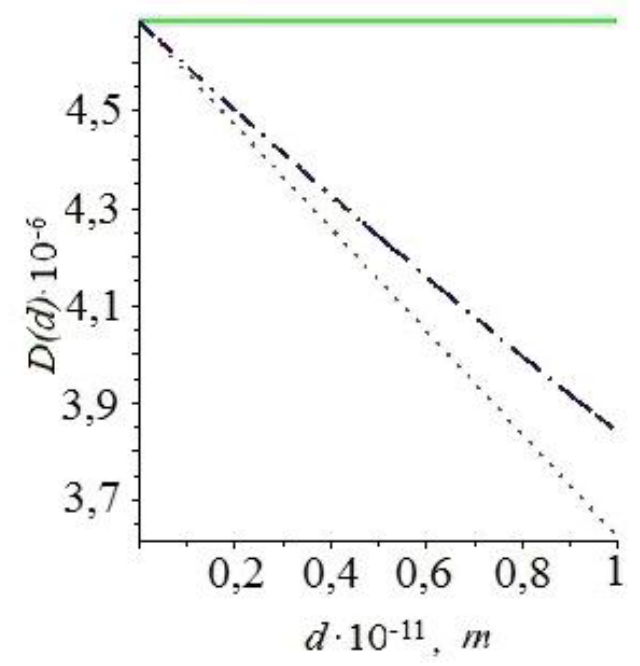

Fig.2. Graphs of dependence of the coefficient of transparency of the barrier on $d$

The current density, which is determined by the expression (2) taking into account (11) at

$$
N(W)=\frac{m}{2 \cdot \pi^{2} \cdot \hbar^{3}} \cdot(\mu-W),
$$

in general case depends on parameters: $F, \mu, \chi, d$, $h$. On condition $d<<d_{0}(W)$, the expression for the current density of the field emission has the form:

$$
j=j_{F-N} \cdot\left(1-\frac{d}{d_{0}(\mu)}\right) .
$$

The dependence of the current density (16) on the electric field strength is shown in Fig.3 (a continuous curve). One can take $C=12 \mathrm{eV}, \mu=$ $7.5 \mathrm{eV}, \chi=4.5 \mathrm{eV}, d=10^{-11} \mathrm{~m}$. Curve, depict by dots, describes the current density FowlerNordheim $j_{F-N}$. As can be seen from Fig.3, the 
current density $j$ of the field emission decreases by 1.3 times relative to the value $j_{F-N}$ at the value of the electric field strength $E \in\left[5 \cdot 10^{9} ; 10^{10}\right] \mathrm{V} / \mathrm{m}$.

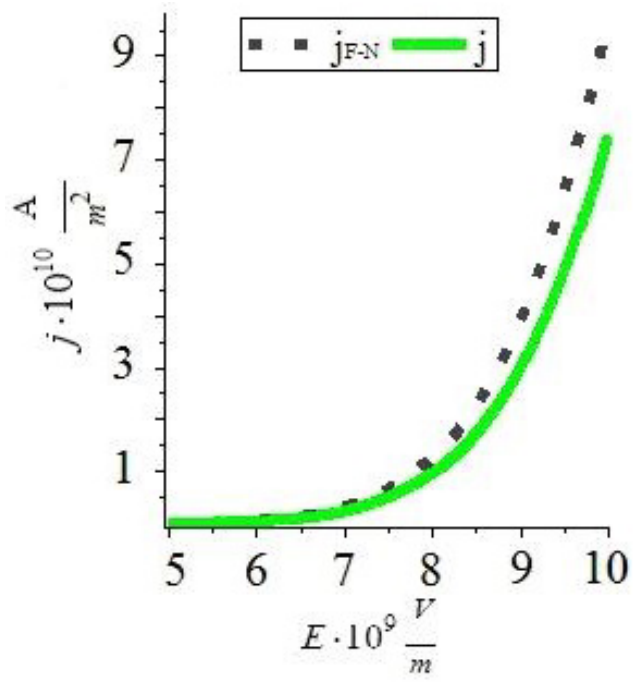

Fig.3. Comparison of the dependences of the field emission current density from the modified metal surface to vacuum and for the metal-vacuum system

\section{CONCLUSIONS}

The model of a potential barrier of a metal with an additional near-surface dipole layer is proposed in the present work. It is possible to use the introducing such layer in order to describe the metal with modification of the metal surface. An analytic generalization of the Fowler-Nordheim formula in the case of the potential barrier, which is depicted in Fig.1, was done. The analytic equations of the coefficient of transparency of the potential barrier and the field emission current density were found on condition $d<<d_{0}(\mu)$ with taking into account an additional near-surface dipole layer. It is shown that the field emission current decreases by 1.3 times relative to the value $j_{F-N}$ for considering the potential barrier at $d=10^{-11} \mathrm{~m}$.

\section{ACKNOWLEDGEMENTS}

Publication is based on the research provided by the grant support of the State Fund For Fundamental Research as well as by the National Academy of Sciences of Ukraine (NASU) under the program of cooperation between NASU, CERN and JINR «Nuclear matter in extreme conditions» under Contract CO-1-16/2017.

\section{References}

1. R. H. Fowler, L. Nordheim Electron Emission in Intense Electric Fields // Proceedings of the Royal Society of London. Series A, Containing Papers of a Mathematical and Physical Character. 1928, v.119, N781, p.173-181.

2. M. Kidemo. New spark-test device for material characterization // Nucl. Instrum. And Methods A. 2004, v.530, p.596-606.

3. P. N. Burrows. Updated baseline for a staged Compact Linear Collider: CERN, 2016.

4. W. Wuensch, A. Degiovanni, S. Calatroni, A. Korsback, F. Djurabekova, R. Rajamaki, J. GinerNavarro. Statistics of vacuum breakdown in the high-gradient and low-rate regime // Physical Review Accelerators and Beams. 2017, v.20, p.011007.

5. F. J. Blatt. Field emission in a magnetic field // Phys. Rev. 1963, v.131, p.166-169.

6. S. O. Lebedynskyi, V. I. Miroshnichenko, R. I. Kholodov, V. A. Baturin. The effect of a magnetic field on the motion of electrons for the field emission process description // Probl. At. Sci. Tech. 2015, v.14(98), p.62-66.

7. A. Yu. Antonov, S. R. Antonov, D. V. Zhukov. Modeling of characteristics of field emission systems of tungsten-cesium // Vestnik of St. Petersburg University. series 10: applied mathematics, computer science, management processes. 2006, v.1, p.16-25 (in Russian).

8. O. E. Raichev. Coulomb blockade of field emission from nanoscale conductors // Phys. Rev. 2006, v.B73, p.195328.

9. Al. A. Zakhidov, A. N. Obraztsov, A. P. Volkov, D. A. Lyashenko. Mechanism of low-voltage field emission from nanocarbon materials // JETP. 2005, v.127, p.100-106 (in Russian).

10. L. D. Landau, E. M. Lifshitz. Quantum Mechanics (Volume 3 of A Course of Theoretical Physics), Pergamon Press, 1965.

\title{
ТЕОРЕТИЧЕСКОЕ ИЗУЧЕНИЕ ВЛИЯНИЯ МОДИФИКАЦИИ ПОВЕРХНОСТИ МЕТАЛЛА НА ВЕЛИЧИНУ ТОКА ПОЛЕВОЙ ЭМИССИИ В ГРАДИЕНТНО-УСТОЙЧИВЫХ УСКОРЯЮЩИХ СТРУКТУРАХ
}

\author{
И. И. Мусиенко, Р. И. Холодов
}

Решена квантово-механическая задача о движении электрона через модельный потенциальный барьер системы металл-вакуум с введением дополнительного приповерхностного дипольного слоя. Учитывая 
условия непрерывности волновых функций и их производных на границе раздела двух сред, получены общие выражения коэффициента прозрачности потенциального барьера и плотности тока полевой эмиссии в пределах данной модели. Показано влияние эффективной толщины дипольного слоя поверхности металла на значение плотности тока полевой эмиссии.

\section{ТЕОРЕТИЧНЕ ВИВЧЕННЯ ВПЛИВУ МОДИФІКАЦІЇ ПОВЕРХНІ МЕТАЛУ НА ВЕЛИЧИНУ СТРУМУ ПОЛЬОВОЇ ЕМІСІЇ В ГРАДІЕНТНО-СТІЙКИХ ПРИСКОРЮЮЧИХ СТРУКТУРАХ}

\section{І. І. Мусієнко, Р. І. Холодов}

Розв'язана квантово-механічна задача про рух електрона через модельний потенціальний бар'єр системи метал-вакуум з введенням додаткового приповерхневого дипольного шару. Враховуючи умови неперервності хвильових функцій і їх похідних на межі розділу двох середовищ, одержано загальні вирази коефіцієнта прозорості потенцйного бар'єра та густини струму польової емісії в рамках даної моделі. Показано вплив ефективної товщини дипольного шару поверхні металу на значення густини струму польової емісії. 